\title{
LAS CORPORACIONES LOCALES Y LOS SEGUROS SOCIALES
}

(Continuación).

\section{SUBSIDIO FAMILIAR}

1. Normas legales.-Los dos avances más considerables del Estado nacionalsindicalista español en orden a la Previsión social, lo constituyen, indudablemente, el aumento de pensión en el régimen de ayuda a la ancianidad, que ya hemos expuesto, y el establecimiento del Subsidio Familiar.

Fué creado este régimen obligatorio por la Ley de Bases de 18 de Julio de 1938, que, dirigiéndolo a la elevación y fortalecimiento de la familia, lo implantó sobre amplísima base, en reconocimiento -como acertadamente dijo-al "principio de hermandad entre los hombres de España". Su Reglamento general lleva fechā de 20 de octubre del mismo año. $Y$ nos merecen también un especial interés otras normas legales destinadas a regular diversos aspectos del mismo, ya concretadas a empleados y obreros del Estado y las Corporaciones locales, ya por contener preceptos aplicables también a éstos: entre las primeras, mencionaremos: la Orden circular del Ministerio del Interior, de 22 de noviembre de 1938, ordenando formar un censo de tales trabajadores, con sus cargas familiares; las Ordenes de la Vicepresidencia, de 25 de noviembre de 1938, relativa también al período preparatorio, y de 3 de marzo de 1939, señalando la fecha del primer pago; la del Ministerio de la Gobernación de 7 de marzo del mismo año, relacionada con la anterior; la del Ministerio de Organización y Acción Sindical, de 14 de marzo de 1939, dando normas para el pago del Subsidio; y la Orden de 25 de septiembre de 1940, relativa a las viudas y huérfanos de funcionarios públicos.

Entre las normas cuyo contenido excede de preceptos relativos a los trabajadores por cuenta del Estado y las Corporaciones locales, pero que presentan interés para nuestro estudio, debemos recordar como más importantes: 
Rama Agro-pecuaria: Ley de $1 .^{\circ}$ de septiembre de 1939, Orden de 6 de octubre del mismo año, y Decreto de 5 de mayo de 1941.

Rama de Viudedad y Orfandad: Ley de 23 de septiembre de 1939 y Orden del 7 de diciembre siguiente.

Retroactividad: Decreto de 22 de febrero de 1941, y Ordenes de 8 y 10 de marzo y 11 de junio del mismo año.

2. Campo de aplicación.-Hemos señalado ya la muy amplia base sobre la que se organiza el Régimen de Subsidio Familiar. La Ley inicial dispuso: "Tendrán derecho al subsido los trabajadores por cuenta ajena, cualquiera que sea su estado civil, edad, sexo, forma y cuantía de la remuneración y clase de trabajo, que tengan hijos c asimilados a ellos que vivan a su cargo y en su hogar, y que sean menores de catorce años." El Reglamento confirma esta amplia concepción: "Serán asegurados obligatoriamente todos los españoles que trabajan por cuenta ajena..."

Estas normas implican ya la necesidad de comprender a las Diputaciones y Ayuntamientos, señalada además concretamente por los artículos $49^{\circ}$ a $80^{\circ}$ del Reglamento general. Disponiendo este texto legal, que por el Consejo de Ministros habrían de dictarse normas especiales para la aplicación del régimen a los funcionarios y toda clase de trabajadores del Estado, de la Provincia y del Municipio.

3. Régimen especial de las Corporaciones locales.-El ya citado artículo $4 .^{\circ}$ del Reglamento, puesto en relación con el 51 y siguientes del mismo, preveía dos sistemas distintos pàra las Corporaciones locales: el de acogerse al régimen común de la Caja Nacional de Subsidios Familiares, realizando directamente, dentro de él, el pago de los subsidios, y el de abonar a sus trabajadores, también de modo inmediato, subsidios mínimos equivalentes a los del Régimen ordinario, quedando fuera de éste. La opción debía ser acordada en un período comprendido entre el $1 .^{\circ}$ de noviembre de 1938 y el 31 de enero de 1939; a falta de opción expresa, se presumía hecha a favor del régimen común de la Caja Nacional de Subsidios Familiares.

Este sistema está hoy fundamentalmente modificado, y sin que el examen de las normas legales nos muestre un precepto terminante derogatorio de los artículos citados y de la opción establecida, es lo cierto que el único régimen hoy vigente para las Corporaciones locales es el que podemos llamar "especial", y en virtud del cual las Diputaciones y Ayuntamientos, igual que los Cabildos, abonan con cargo a sus propios fondos los subsidios correspondientes a los trabajadores a su servicio, descontándoles a sí mismos el uno por ciento de sus haberes, conforme a las normas que indicaremos. 
4. Personas a quienes afecta. - Como "asegurados", es decir, como trabajadores a quienes deben descontarse por las Corporacio nes las correspondientes cuotas-definición poco técnica, pero probablemente práctica-, es preciso considerar a todos los funcionarios, empleados y obreros, cualquiera que sea su categoría y destino, incluso los que tengan el carácter de eventuales, que perciban sus haberes o jornales sin distinción de cuantía, con cargo a partida o concepto que figure en los respectivos presupuestos. Concepto . al que llegamos por una adecuada conjugación del art. 5. ${ }^{\circ}$ del Reglamento y de las definiciones contenidas en las Ordenes de 3 y 14 de marzo de 1939. En cuanto a los trabajadores extranjeros, debe estarse en general al criterio de reciprocidad establecido en el art. 9. del Reglamento, y al de equiparación para los súbditos portugueses, los de Andorra y los de los países hispano-americanos.

Como "subsidiados"-personas a quienes las Corporaciones deben satisfacer subsidio-, tenemos:

1. Los asegurados que tengan a su cargo dos o más "beneficiarios". Tienen el carácter de beneficiario, en primer término, los hijos: legítimos, naturales reconocidos y los de la cónyuge; resulta dudoso si deben ser equiparados a ellos los adoptivos, ya que si a ello incita un sentimiento de justicia y de analogía de situación, e incluso de conformidad con el criterio mantenido en otros seguros sociales (véase el art. 29 del Reglamento de Accidentes del Trabajo en la Industria), los términos precisos en que aparece redactado el art. 11 del Reglamento, suponen un grave obstáculo para tal equiparación.

Tienen asimismo el carácter de beneficiarios, los nietos o hermanos del asegurado que no tengan por otros motivos derecho al subsidio y cuyos padres hayan muerto o estén incapacitados para el trabajo. ¿Debe exigirse una incapacidad absoluta o es suficiente con la que deba calificarse como de total para su trabajo habitual? En favor de la primera tesis parece abonar un criterio de analogía con la exigencia de tal clase de incapacidad para que los mayores de catorce años puedan ser considerados beneficiarios, e incluso el considerar que el legislador ha debido pensar, quizá, en casos de desamparo extremo, ya que al lado de tal incapacidad sólo ha colocado el caso de muerte. En contra, sin embargo, y por lo tanto en favor de una interpretación generosa del precepto, podría alegarse el criterio constante seguido en este punto por los restantes Seguros Sociales, que, o bien declaran expresamente que basta con que la incapacidad sea "total" (art. 2. ${ }^{\circ}$ de la Orden de 6 de octubre de 1939, y 
7.9 de la de 2 de febrero de 1940, en el Subsidio de Vejez), o han sido interpretadas en tal sentido por los órganos de gestión y la propia Jurisprudencia, como ocurre con la base 3." de la Ley y el art. 29 del Reglamento de Accidentes del Trabajo en la Industria, y con el art. 71, apartado c) del Reglamento de Accidentes en la Agricultura, (pueden verse la Sentencia del Tribunal Supremo de 31 de mayo de 1933 y el Acuerdo de la Comisión Revisora Paritaria Superior de Previsión de 21 de noviembre de 1934).

Tanto unos como otros deben vivir en España, en el hogar del subsidiado, y tener menos de catorce años o sufrir invalidez absoluta para el trabajo desde antes de haber cumplido dicha edad.

2. Las trabajadoras en activo, aseguradas, viudas, que tengan a su cargo un solo hijo menor de catorce años. La norma legal no prevee el caso de que este hijo sea mayor de dicha edad y sufra desde antes de cumplirla incapacidad absoluta. ¿Tendrá el carácter de beneficiario?; estimamos que sí, por razón de analogía.

3. Los trabajadores asegurados, huérfanos de padre, que tengan a su cargo madre viuda, mayor de cincuenta años, o hermanos huérfanos menores de catorce.

4. Las viudas de quienes hubiesen sido funcionarios públicos al servicio de las Diputaciones o Ayuntamientos, siempre que reúnan las condiciones exigidas por la Ley de 23 de septiembre de 1939 y Orden de 7 de diciembre del mismo año. iY de las que lo sean de empleados $u$ obreros, no funcionarios, que hubiesen estado al servicio de las Corporaciones locales? La Orden de 7 de septiembre de 1940 se refiere tan sólo a las que lo sean de "funcionarios", concepto más restringido, indudablemente, que el de trabajador en general. $¿$ Cabe interpretación analógica? Posiblemente resulta excesiva.

5. Los huérfanos de padre y madre, menores de catorce años, cuando aquél o ésta hayan sido funcionarios de las citadas Corporaciones y reúnan las circunstancias previstas en dichas disposiciones. Se nos presentan las mismas dudas que en el grupo anterior en cuanto a una posible extensión a los huérfanos de asalariados no funcionarios.

Resulta interesante dejar consignada que el percibo de pensión de viudedad u orfandad del Estado o de las Corporaciones o Entidades oficiales o particulares, priva del derecho al Subsidio en los dos últimos casos.

Ninguna particularidad especial nos ofrecen estos grupos, fuera de las dichas, respecto al régimen común. Los criterios de interpre‘5 tación que para éste resulten de los acuerdos de la Dirección Gene- 
ral de Previsión serán útiles para determinar las obligaciones en casos análogos de las Diputaciones, Cabildos y Ayuntamientos.

Respecto a los trabajadores agrícolas, la Ley de $10^{\circ}$ de septiembre de 1939-Ley distinta de la que en la misma fecha estableció el Subsidio de Vejez-, dispuso que el régimen de Subsidios Familiares aplicable a los mismos quedaria organizado en forma de cuotas exclusivamente patronales, proporcionales a la Contribución Territorial. La Orden de 6 de octubre del mismo año ordenó en su artículo $90^{\circ}$ que la aplicación de la Ley antes citada se iniciaría el $1 .^{\circ}$ de enero de 1940; "hasta dicha fecha subsistirá el procedimiento administrativo actuál. La modificación del sistema-seguía diciendono exime a los obligados por la Ley de abonar las cuotas que les correspondan hasta el 31 de diciembre próximo".

Más tarde, la Orden de 17 de enero de 1940 prorrogó la vigencia del procedimiento administrativo establecido en el Reglamento general, hasta tanto se promulgase la disposición fijando la implantación total del régimen especial agro-pecuario. El Decreto de 5 de mayo de 1941 fijó los tipos contributivos, en forma global para este régimen y el de Subsidio de Vejez, y declaró como fecha inicial la de $1 .^{\circ}$ de enero del propio año.

Actualmente se halla en período de organización el mecanismo administrativo que este régimen, con sus difíciles problemas, exige. Es de esperar que nuevas normas legales vengan a fijar, definitiva o provisionalmente, la situación y aplicación del mismo; y estas disposiciones habrán de regular o aclarar al menos cuáles son los derechos y obligaciones de las Corporaciones locales respecto a este grupo de trabajadores, que tanta atención merecen y están recibiendo de los órganos estatales.

El reconocimiento del derecho al Subsidio a los trabajadores de toda clase al servicio de las Corporaciones públicas, objeto de este artículo, corresponde a la Caja Nacional de Subsidios Familiares. A ella deberán remitirse por los respectivos secretarios de las Diputaciones, Cabildos y Ayuntamientos, las Declaraciones de Familia, que el interesado debe formular por triplicado, firmadas también por el indicado funcionario.

5. Pago del Subsidio.-Se aplican para determinar su cuantía las escalas semanal y mensual ordinarias, tal como han sido fijadas por el Decreto de 22 de febrero de 1941 ("B. O." del 7 de marzo), que elevó en un 100 por 100 las señaladas por la Ley de Bases. Conforme a la legislación del Subsidio, nada impide a las Corporacio- 
nes locales, en uso de su autonomía, conceder Subsidios superiores a los legales.

La Orden de 14 de marzo de 1939 precisa la forma de hacerse los pagos, debiendo tenerse en cuenta que la escala semanal a que la misma se refiere ha sido suprimida, aplicándose la mensual para los que trabajen para una Corporación más de cinco días al mes (Orden de 6 de diciembre de 1939 y Decreto de 22 de febrero de 1941).

Puede ocurrir que algunos trabajadores lo sean simultáneamente para varias Corporaciones locales, o para una o varias y el Estado, o para alguna de ellas y Empresas particulares. En este último caso, el Subsidio deberá ser satisfecho en todo caso por la Diputación, Cabildo o Ayuntamiento. En los anteriores, por la entidad de quien perciban una remuneración más elevaḍa. La norma legal no ha previsto el caso de que sean iguales, aunque éste, indudablemente, será raro.

En febrero de 1941, al mismo tiempo que se duplicaban, como hemos dicho, la cuantía de los Subsidios, se concedió a cada familia trabajadora subsidiada, de una sola vez, el 50 por 100 del total importe de lo que hubiesen cobrado desde la implantación del régimen hasta el 31 de marzo de dicho año. Para regular esta mejora, se dictaron diversas disposiciones, que señalaron normas específicas para las Corporaciones locales, en cuyo examen no creemos necesario entrar, ya que tuvieron, por propia naturaleza y finalidad, un carácter transitorio, poco interesante, prácticamente, en la actualidad.

6. Descuento a los trabajadores.-En el régimen ordinario, los asegurados contribuyen a los fondos del Subsidio con el 1 por 100 de sus haberes. Criterio análogo se sigue respecto a los que son trabajadores por cuenta de Corporaciones locales, a quienes, en el momento del pago, debe hacerse igual descuento, a favor de aquéllas, en el importe nominal de sus haberes. Por expresa declaración de la Orden de 14 de marzo de 1939 no se computará como retribución a estos efectos las indemnizaciones por residencia $\mathrm{y}$ dietas. $\mathrm{Y}$ tampoco deben ser tenidas en cuenta, a efectos de computación, las gratificaciones o pagas extraordinarias, pluses por carestía de vida y demás percepciones, siempre que lo sean en concepto de excepcionales y obedezcan expresamente a causas circunstanciales motivadas por la anormalidad económica, ya que así lo ha dispuesto, en términos generales, la Orden de 7 de marzo de 1942, sin que exista motivo serio alguno para no considerarla aplicable a los trabajadores de las Corporaciones de que venimos ocupándonos.

7. Obligación específica.-Tienen las Diputaciones, Cabildos y 
Ayuntamientos, igual que los departamentos ministeriales, civiles y militares, una obligación que no se impone a las restantes entidades patronales, basada, sin duda, en el especial régimen a que las mismas están sujetas, con mínima intervención de la C. N. de S. F.: la de formalizar semestralmente una estadística para dicha Caja, en la que conste al 30 de junio y 31 de diciembre, el número de funcionarios y trabajadores de su plantilla, y nóminas, por sexo, estado civil y. condición profesional; el número de subsidiados, clasificados por beneficiarios; el importe total de sueldos y salarios y el de. Subsidio abonado.

\section{SEGURO DE ACCIDENTES DEL TRABAJO}

1. Antecedentes.-La legislación española sobre reparación de accidentes del trabajo se inicia, con la. Ley de 30 de enero de 1900 , desarrollada por el correspondiente Reglamento, que lleva fecha de 28 de julio del mismo año.

Resultaría excesivo afirmar que nacía con ella un seguro social, ya que dichas normas, aplicables exclusivamente a los trabajadores de la industria y, sólo por excepción, a labores agrícolas en determinadas circunstancias (sentencias de 12 de diciembre de 1905, 3 de junio de 1909 y otras), se limitaban simplemente a establecer un sistema de reparación, sin seguro obligatorio alguno.

Este deber de indemnizar se hacía extensivo a las Corporaciones locales: "Los preceptos de esta Ley-establecía su artículo 13-obligarán al Estado en. sus arsenales, fábricas de armas, de pólvora y en los establecimientos o industrias que sostenga. Igual obligación tendrán las Diputaciones provinciales y Ayuntamientos, en los respectivos casos, así como en las obras públicas que ejecuten por administración". $\mathrm{Y}$ el párrafo final del artículo $10^{\circ}$ del Reglamento, al definir al patrono, afirmó: "el Estado, las Diputaciones provinciales y los Ayuntamientos quedan equiparados para los efectos de este artículo a los particulares y compañías".

La tendencia en el campo internacional, igual que en la doctrina, ha sido y es favorable a este sistema de amplia base de aplicación. El Convenio conseguido en la Conferencia Internacional del Trabajo de Ginebra, junio de 1925, ratificado por España en 22 de febrero de 1929, establece también la necesidad de comprender en las legislaciones sobre reparación a los obreros, empleados o aprendices ocupados por las empresas, explotaciones o establecimientos, de cualquier naturaleza que sean, públicas o privadas; excluyendo, sin embargo, a aquellas personas que gocen de un régimen especial 
equivalente, cuando menos, al que el propio Convenio regula (artícu$\operatorname{los} 2 .^{\circ}$ y $\left.3 .^{\circ}\right)$.

En España, el criterio recogido en la legislación de 1900 se mantiene constante, con alteraciones que no interesa a nuestro objeto consignar, hasta la pasada década, en la que señala un avance muy considerable en esta materia, pudiéndose hablar ya desde entonces de la existencia en nuestra Patria de un verdadero seguro social para la reparación de los accidentes del trabajo.

2. Legislación vigente.-Al examinar el sistema legal válido en la actualidad en España, es preciso, ante todo, distinguir, en atención a sus campos de aplicación respectivos, tres tipos de accidentes del trabajo:

a) Accidentes del trabajo en la industria. Se rigen por la Ley de 8 de octubre de 1932, que desarrolló las bases establecidas por la Ley de 4 de julio anterior; el Reglamento de 31 de enero de 1933, y múltiples disposiciones posteriores, algunas de las cuales habremos de citar en momento oportuno.

b) Accidentes de trabajo en la Agricultura. Están regulados por las Bases aprobadas por Decreto de 12 de junio de 1931, elevado a. Ley por la de 9 de septiembre siguiente; Reglamento de 25 de agosto del mismo año; y disposiciones posteriores de menor importancia.

c) Accidentes de trabajo en el mar. Su norma fundamental es el Decreto de 4 de junio de 1940.

Expondremos en primer término las particularidades más interesantes que respecto a las Corporaciones locales ofrece la legislación de accidentes de trabajo en la Industria, y a continuación las de la Agricultura. En cuanto a los accidentes del trabajo en el mar, nos limitaremos a una brevísima referencia, ya que, como resulta innegable, ofrecen a nuestro objeto un interés muy reducido.

3. Accidentes del trabajo en la Industria. Para la más clara exposición, estudiaremos la materia dividida en los siguientes puntos:

A) Carácter de las Corporaciones locales: La atribución de la calificación jurídica de patrono a las Corporaciones locales, propietarias de la obra, explotación o industria donde el trabajo se presta, resulta taxativamente establecida en el artículo $2 .^{\circ}$ de la Ley y en el también 2. del Reglamento, "incluso-dicen ambos-en las obras públicas que ejecuten por administración”. La hipótesis de que tales Corporaciones merezcan, conforme al principio también consignado en términos generales en dichos preceptos, el calificativo de patro- 
nos, por ser contratistas de la ejecución o explotación de la obra o industria, será, indudablemente, mucho menos frecuente.

Esta conceptuación jurídica que las normas legales les atribuye, colócanlas, en general, en un plano de igualdad con las restantes entidades patronales; sujetas, en consecuencia, al cumplimiento de las obligaciones que a este elemento de la relación laboral se imponen en tal legislación.

B) Trabajadores por quienes responden.-Cabe establecer una regla general, una regla especial y una excepción.

1) La regla general podemos enunciarla en los términos siguientes: Las Corporaciones locales asumen las obligaciones patronales en todas las industrias o trabajos en quienes, en iguales casos, lo hacen las restantes entidades patronales, tal como resultan relacionadas aquéllas en el artículo $7 .^{\circ}$ del Reglamento, y por todos los operarios definidos en el artículo $3 .^{\circ}$ de la Ley y definidos y enumerados en el artículo $3 .^{\circ}$ del Reglamento.

2) La regla especial la constituye la responsabilidad de las Diputaciones, Cabildos y Ayuntamientos en los accidentes indemnizables sufridos por los agentes de la Autoridad que estén a su servicio, y se caracteriza por quedar limitada a aquellos casos en que tales asalariados no gocen, por disposiciones especiales, de auxilios equivalentes a lo otorgado por la Ley (arts. $4 .^{\circ}$ de la Ley y del Reglamento).

El mismo criterio rige para ciertos operarios a quienes se otorgue la consideración de agentes de la Autoridad, aun cuando no sean pagados por la Corporación, tales como serenos o vigilantes nocturnos. Igual que los demás agentes, deben ser incluídos en el correspondiente seguro, siempre que no gocen de aquellos beneficios especiales (artículo 248 del Reglamento).

Dados los términos de estos preceptos, parece será indiferente la autoridad de que emanen tales disposiciones especiales, siempre que tenga facultades para dictarlas; $y$, por tanto, el reconocimiento que hagan las propias Corporaciones de los auxilios mencionados, en virtud de sus poderes autonómicos, les eximirá de las responsabilidades ordinarias previstas en la legislación común de accidentes.

3) Excepción: En virtud de las normas establecidas en los artículos $3 .^{\circ}$ (apartado $80^{\circ}$ ) y $7 .^{\circ}$ (apartado 14) del Reglamento, los empleados de oficina sólo quedaron comprendidos en los beneficios otorgados por la legislación de Accidentes del trabajo en la Industria cuando prestasen sus servicios en oficinas o dependencias de fábricas, o establecimientos industriales, con sueldo inferior a cinco mil 
pesetas anuales, y para el solo caso de que fuesen víctimas de un accidente ocurrido en dichas fábricas, talleres o explotaciones como consecuencia de los trabajos que de ordinario se ejecutan en los mismos.

Estas limitaciones han quedado en parte suprimidas por la Orden de 13 de junio de 1934-norma de discutible eficacia y validez desde el punto de vista de la jerarquización de preceptos-, que declara aplicables los beneficios legales a todos los empleados de oficina en general, sin distinción de los establecimientos en que presten sus servicios y siempre que su remuneración no exceda de $\mathbf{1 5}$ pesetas diarias. Ninguna duda cabe de que esta Orden alcanzaba a las Corporaciones locales, ya que ninguna excepción hace. Su derogación fué pedida por diversos Ayuntamientos, fundados en que conceden, o concedían en aquel entonces, derechos en sus Reglamentos a los empleados víctimas de ciertos accidentes; la Orden de 27 de noviembre del propio año rechazó la indicada solicitud.

Tiende la disposición de 13 de junio de 1934 a establecer un criterio de igualdad; mas al no tener en cuenta la existencia de tales Reglamentos, vino a caer en una desigualdad contraria, ya que ciertos empleados resultaron colocados en una situación privilegiada al recibir reparaciones por dos distintos conceptos cuando se accidentaban.

Para restablecer en este punto la solución justa cabían dos caminos: el de declarar exceptuados a tales trabajadores de la legislación común de accidentes, colocándolos en situación análoga a la que tenían antes de la Orden de 1934, o el de obligar a las Corporaciones a borrar de sus Reglamentos los apuntados beneficios. Por el primero, se ha pronunciado la Orden de 22 de enero de 1941, que declara exceptuados de lo dispuesto en la de 13 de junio de 1934 a los empleados administrativos de los Ayuntamientos, Diputaciones y Cabildos que en sus Reglamentos respectivos tengan cubiertos los riesgos de incapacidades y muerte en la cuantía y condiciones establecidas en el Reglamento de accidentes.

La repetida Orden de 1934 será, pues, aplicable cuando tales Reglamentos no concedan auxilios o los concedan en cuantía insuficiente. Además, y por aplicación de los principios generales de nuestro Derecho, que niegan fuerza retroactiva a las disposiciones legales si éstas no lo establecen expresamente, tendrán derecho a las indemnizaciones prescritas en la legislación general los accidenta64 dos en el período transcurrido desde la fecha en que entró en vigor 
la Orden de 1934 y el día en que lo hizo la de 1941, aunque acrediten también derechos conforme a sus respectivos Reglamentos.

No faltan declaraciones jurisprudenciales que hayan venido a resolver algunos puntos dudosos. Ofrece entre ellas bastante interés la Sentencia de 7 de julio de 1931; en la que el Tribunal Supremo fijó su posición en los casos de accidentes ocurridos con motivo de las prestaciones personales que los Ayuntamientos pueden establecer.

El criterio del alto Tribunal es contrario a admitir que pueda hablarse aquí de obrero a efectos de idemnización: "El lesionado, en este caso-dice-, trabaja en virtud de un precepto legal que impone contribuir con el esfuerzo personal de los vecinos al cumplimiento de servicio de interés y beneficios comunes encomendados a una entidad administrativa, lo que no puede reputarse consecuencia de un contrato, sino del cumplimiento de un deber, careciendo además ese trabajo de los requisitos de habitualidad, al ser temporal y no profesional, de verificarse por cuenta ajena, ya que las cualidades de patrono y obrero se confunden al trabajarse en el régimen de mutualidad por y para los vecinos de la localidad en que el trabajo se realiza, y de fijarse retribución constitutiva del precio cierto que para la existencia del contrato de trabajo exige el art. $10^{\circ}$ del Código que lo regula, todo lo cual impide reputar obrero, a los efectos de la indemnización por accidente, a quien lo sufrió en ese trabajo". Hagamos notar que; por la fecha de la sentencia, alguna referencia resulta inactual; sin embargo, los nuevos textos legales no modifican sustancialmente las bases en que aquélla se apoya.

Sobre agentes de la Autoridad pueden ser consultadas las sentencias de 21 de marzo y 13 de junio de 1927.

C) Seguro obligatorio: Conforme al art. 87 del Reglamento, todo patrono comprendido en las disposiciones del mismo tiene obligación de estar asegurado contra el riesgo de incapacidades permanentes y muerte de sus operarios, producidas por accidentes del trabajo. $\mathrm{Y}$ el art. 90 concede tres modalidades distintas para cumplir tal deber: el seguro directo con la Caja Nacional de Seguro de Accidentes del Trabajo, el realizado mediante la inscripción en $\mathrm{Mu}$ tualidad patronal y el contratado con una Sociedad de seguros legalmente constituída.

Mas esta facultad de èlección no se acepta-con lógico criteriorespecto a las Corporaciones locales, que, igual que el Estado y otras cualesquiera Administraciones públicas, están obligadas a realizar el seguro en la Caja Nacional (art. 91 del Reglamento). Siendo nu- 
las las polizas que, en contravención con este precepto, celebren las Corporaciones con entidades distintas de la Caja, incurriendo además en responsabilidad sus elementos gestores y los Secretarios que no advirtiesen la ilegalidad de tales acuerdos (Decreto de 8 de octubre de 1935 , art $2 .^{\circ}$ ). Del cumplimiento de tal obligación no pueden eximirse en ningún caso las Diputaciones y Ayuntamientos, cualquiera que sea la solvencia económica que ofrezcan y los beneficios que concedan en sus Reglamentos a los obreros o empleados que sufran accidentes del trabajo. (Pueden consultarse sobre este punto las Ordenes de 4 de agosto de 1934-“Gaceta" del 19-y de 15 de febrero de 1940.).

En cuanto a las incapacidades temporales, el seguro de su responsabilidad es voluntario para los patronos, que pueden asumir de modo inmediato y directo, si así lo desean, la indemnización de las mismas. La Caja Nacional, que sólo podía reglamentariamente actuar como aseguradora de incapacidades permanentes y muerte, vió modificado en este punto sus Estatutos por la Orden de 16 de febrero de 1940, que declaró facultativo para la misma la aceptación de los riesgos del seguro de incapacidad temporal. Cuando la ejecución y explotación de las obras 0 industrias se realicen por medio de contratista, éste, que tiene, como antes hemos dicho, el carácter de patrono (art. $20^{\circ}$ del Reglamento), deberá estipular el correspondiente seguro. Y resulta del mayor interés para las Corporaciones propietarias de tales obras, explotaciones o industrias, el exigir terminantemente el cumplimiento por el contratista de tal obligación, ya que puede ocurrir, y ha ocurrido, que por no haber contratado aquel seguro y resultar insolvente sean las propias Corporaciones quienes soporten las consecuencias económicas del accidente que ocurra, en virtud de la responsabilidad subsidiaria que las normas reglamentarias imponen. En los casos en que hayan ocurrido accidentes puede resultar conveniente para las Diputaciones y Ayuntamientos el informarse en la Caja Nacional de si han sido cubiertas las responsabilidades de aquél, antes de reintegrar al contratista la fianza depositada.

D) Retroactividad: $\mathrm{El}$ artículo adicional de la Ley de 8 de octubre de 1932, señaló como fecha para su entrada en vigor la de $1 .^{\circ}$ de abril de 1933.

Teniendo, sin duda, en cuenta que la formalización del seguro con la Caja Nacional se impone como obligatoria a las Corporaciones públicas, la disposición transitoria del Decreto de 26 de julio de 1934, que añadió al Reglamento un nuevo capítulo, dispuso que 
tal seguro se entendía hecho para todos los efectos desde la fecha antes señalada. En consecuencia - añadia-, la Caja Nacional constituirá las rentas correspondientes a los siniestros que hayan ocurrido desde dicha fecha, y los Ministerios, Corporaciones o servicios satisfarán a dicha Caja las primas correspondientes. Este precepto fué reconocido de cumplimiento ineludible por la Orden de 27 de septiembre de 1935.

Conforme a estas normas, el Seguro de las Corporaciones locales en la repetida Caja Nacional se estimaba, de derecho, en todo caso como existente, ya que cualquiera de las partes interesadas padía exigir lo que constituye la esencia del mismo, o sea las prestaciones que impone respectivamente a la parte contraria.

Estos preceptos resultan modificados por la Orden de 29 de agosto de 1938, aclarada por la de 14 de febrero de 1940. A su tenor, la legalidad vigente es la siguiente:

1) Las Diputaciones, Cabildos y Ayuntamientos gozaron de un plazo de treinta días para formalizar la oportuna póliza con la Caja Nacional. Este plazo comenzaba a contarse para las Corporaciones liberadas con anterioridad a la Orden de 29 de agosto, a partir de la publicación de la misma; y para las que lo fueron después, a partir del momento de su liberación.

El incumplimiento de tal obligación, exime a la Caja Nacional de toda responsabilidad por los siniestros ocurridos a los asalariados de las Corporaciones negligentes. Por lo tanto, las Diputaciones o Ayuntamientos que no formalizaron las pólizas en tales períodos no pueden obligar a la Caja a hacerse cargo de siniestro alguno anterior al día en que la formalicen o la hayan formalizado, tanto ocurriese el accidente antes de la Orden de agosto de 1938 como después de ella.

Contratada la póliza en aquellos plazos, y pagadas las primas, la Caja responde de todos los siniestros posteriores a la fecha de liberación de la Corporación contratante.

Punto discutible resulta determinar si, habiendo realizado el seguro en aquellos plazos a que nos hemos referido, podría obligar a la Caja a responder de accidentes anteriores al 18 de julio de 1936 o a la fecha de liberación respectiva, mediante el pago de las primas a partir de $10^{\circ}$ de abril de 1933 . Prácticamente, el problema ofrece pequeño interés, ya que en tales contratos con la Caja Nacional se debieron resolver, indudablemente, tales cuestiones.

2) Las Corporaciones que no formalizaron su seguro con la hacerlo. Los Delegados de Hacienda no aprobarán los presupuestos 
hacerlo. Los Delegados de Hacienda no aprobarán los presupuestos de aquellas que no consignen créditos suficientes para atender al pago de las primas del seguro (art. 247 del Reglamento y Orden de 29 de agosto de 1938).

Señalamos incidentalmente, que también están dichos funcionarios obligados a denegar la aprobación de los presupuestos de las Corporaciones locales que no consignen las cantidades necesarias para pago de las indemnizaciones por incapacidad temporal. (Artículo citado del Reglamento.)

3) Cualquiera que sea la fecha en que la póliza quede formalizada, las primas que deberán pagarse serán las correspondientes al tiempo transcurrido desde el 18 de julio de 1936, para aquellas Corporaciones que estuviesen liberadas en tal fecha, y desde los treinta días siguientes a su liberación para las que lo hubiesen sido con posterioridad.

No aparece enteramente claro de los textos legales si el derecho de la Caja Nacional a exigir las primas desde tales fechas puede hacerse efectivo aun en aquellos casos en que rechace accidentes ocurridos en período anterior a la formalización de la póliza. Los términos en que aparece redactada la Orden de 29 de agosto parece dar base para pronunciarse por la afirmativa. El principio básico del seguro, primas por responsabilidạd, queda así dominado por el de sanción a las Corporaciones incumplidoras de sus obligaciones legales, constituyendo un motivo más en favor del gran interés que para ellas ofrece el más exacto cumplimiento de su deber de estar aseguradas.

4) Respecto a las Corporaciones que tuviesen concertado el seguro con anterioridad a la Orden de 29 de agosto de 1938, las primas que deberán pagar a la Caja serán todas las que tengan en descubierto; las fechas iniciales señaladas en el número anterior no son aplicables a este caso, según expresa declaración de la Orden de 14 de febrero de 1940.

E) Obligaciones en caso de accidente: Las Corporaciones locales están obligadas, igual que los demás patronos, a adoptar las medidas posibles de seguridad e higiene del trabajo, conforme a lo preceptuado en el Capítulo III del Reglamento y disposiciones especiales. Tienen además los deberes de asistencia que en el mismo Capítulo se señalan y los de índole administrativa marcados en los artículos 183 y siguientes de aquél, y más especialmente en el Decreto de 13 de octubre de 1938. El cumplimiento de estos deberes presenta para Diputaciones y Ayuntamientos un interés preponderante, da- 
das las sanciones señaladas en las normas legales para los casos de infracción.

4. Accidentes del trabajo en la Agricultura._Igual que hemos hecho con el grupo anterior, dividiremos la exposición en varios puntos.

A) Carácter de las Corporaciones locales: Ni en la Ley ni en. el Reglamento encontramos una disposición análoga a la que veíamos existía en los textos reguladores de los accidentes del trabajo en la Industria. La equiparación de dichas Corporaciones a los restantes patronos resulta, sin embargo, clara: $1 .^{\circ}$, por los amplios términos en que aparece definido el concepto "patrono"' en la Base 1." de la Ley y en el art. $2 .^{\circ}$ del Reglamento; $2 .^{\circ}$, por el carácter supletorio que para lo no previsto en la legislación específica de accidentes del trabajo en la Agricultura, ofrecen las normas relativas a los ocurridos en la Industria.

B) Trabajadores por quienes responde: No existe ninguna excepción que consignar: su responsabilidad es análoga a la de cualesquiera personas físicas o jurídicas que gocen de la condición de patrono en relaciones laborales de carácter agrícola.

C) Seguro obligatorio: $\mathrm{El}$ art. 80 del Reglamento preceptúa obligatorio el seguro, aceptando como formas hábiles para realizarlo, o bien la adscripción a una Mutualidad, o bien el correspondiente contrato con una Compañía legalmente autorizada al efecto. La Caja Nacional no asegura estos riesgos, cuya reparación discurre por cauces totalmente distintos a la de los ocurridos en la Industria.

Entendemos que no existiendo un precepto expreso en contrario, las Diputaciones y Ayuntamientos están autorizadas para realizar el seguro de sus operarios agrícolas en cualquiera de las dos formas indicadas.

Por el contrario, la asistencia médica deberá prestarse por intermedio de Mutualidades locales (art. 12 y 83); las Compañías no pueden sustituir al patrono en estas obligaciones. Las Corporaciones locales quedan así obligadas a ingresar en Mutualidades patronales, si bien pueden eximirse de tal deber cuando concurra alguna de las circunstancias previstas en el art. 84, o sea: que se trate de explotaciones que ocupen diariamente más de cien obreros y tenga mon-

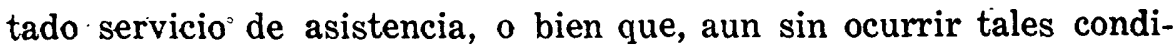
ciones, sean exceptuadas por el Ministerio del Trabajo, por asegurar en cualquier otra forma especial una mayor protección para el obrero. Esta protección creemos se dará frecuentemente, dados los servicios de asistencia normales de los Ayuntamientos y Diputa- 
ciones; pero para ajustarse estrictamente a la Ley, deberán cumplir el trámite que a todo patrono se exige: obtener la excepción del Ministerio del Trabajo.

5. Accidentes del trabajo en el mar.-Son accidentes del trabajo en el mar los que producen "una lesión corporal o la muerte del siniestrado, cualquiera que sea la causa que la origine, estando a bordo o en tierra, con ocasión de las labores complementarias de la navegación o pesca, realizadas por cuenta ajena" (art. $1 .^{\circ} \mathrm{del}$ Decreto de 4 de junio de 1940).

La responsabilidad de las Corporaciones locales, si en algún caso actúan como patronos, la creemos indudable. Lo que nos ofrece alguna duda es el determinar si deben asegurarse necesariamente en la Caja Nacional o pueden hacerlo también en alguna de las entidades aseguradoras inscritas en el Registro de la Dirección General de Previsión. Examinados los arts. $20^{\circ}$ y $5 .^{\circ}$ del Decreto citado, y el $3 .^{\circ}$ de la Orden de 30 de agosto del mismo año, creemos que la solución que parece ajustarse más al contenido y espíritu de tales normas, es la de considerar obligatorio el Seguro en la Caja Nacional cuando se trate de embarcaciones dedicadas a actividades distintas de la de pesca; si por el contrario, los trabajos en que son emṕleadas son los de pescar, la solución no se nos aparece tan clara, y la posibilidad de que puedan estar inscritas en una Mutualidad-no en una Compañía-, puede tener bastante defensa.

Este seguro es independiente del también obligatorio contra los riesgos de guerra, regulado por el Decreto de 23 de febrero de 1940 , Orden de 29 de noviembre del mismo año, $y$ algunas otras.

\section{ACTUACION ESPECIFICA COMO CORPORACIONES PUBLICAS}

Con independencia de sus obligaciones como patronos respecto a los asalariados a su servicio, tienen las Corporaciones que estudiamos otra intervención en los Seguros Sociales, derivada a consecuencia de su carácter de órganos estatales en la esfera local.

Esta actuación queda limitada casi exclusivamente en algunos seguros a certificar o informar sobre la veracidad de ciertas declaraciones de los elementos interesados; en otros, operan como oficinas de recepción y tramitación de determinados documentos, e incluso les están atribuídas ciertas gestiones conducentes al cumplimiento de la legislación del Régimen; en alguno, finalmente, contribuyen con medios propios a las prestaciones legales, en interés general de los asegurados.

1. Subsidio de Vejez-La intervención de los Ayuntamientos, 
o más exactamente de las Alcaldías, ha sido requerida por las normas del Régimen para facilitar la comprobación de los trabajos alegados por los presuntos subsidiados, que intentan acogerse a los beneficios del Subsidio en ciertos casos de carácter realmente transitorio y circunstancial.

En este sentido, la Orden de 3 de julio de 1940, permitió suplir en algunos supuestos la certificación patronal por información testifical practicada ante la Alcaldía del lugar de residencia del interesado o ante la del pueblo donde se prestaron los trabajos. $Y$ la Orden de 12 de enero del presente año, disponiendo la formación de un censo de trabajadores en quienes concurran las condiciones que precisa, exige en su art. 2. vayan acompañadas las instancias de declaraciones de la Alcaldía o Alcaldías, acreditativas de la veracidad de los trabajos constatados en las certificaciones patronales aportadas.

Además, tanto los Ayuntamientos como las Diputaciones, están obligados a exigir de toda Empresa la justificación de que está al corriente en el cumplimiento de sus obligaciones en el Régimen, siempre que tal Empresa pretenda percibir los libramientos que procedan de concesiones, subastas o suministros, u obtener préstamos o anticipos de carácter industrial, mercantil o para la ejecución de obras. (Artículo 37 de la Orden de 2 de febrero de 1940.)

2. Seguro de Maternidad.-Son muy interesantes las obligaciones que las Corporaciones locales asumen en este Régimen con independencia de sus deberes en cuanto patronos. Debemos distinguir las asignadas a los Ayuntamientos y las correspondientes a las Diputaciones.

A) Ayuntamientos. Son las siguientes:

1. Proporcionar a las beneficiarias del Seguro incluídas en la $\mathrm{Be}$ neficencia municipal, y con cargo a su presupuesto por este concepto, la prestación sanitaria del Seguro; y de igual calidad, al menos, que la facilitada directamente por los órganos del mismo.

2. Cuidar por medio de su personal facultativo del reconocimiento de todas las gestantes aseguradas, siendo suficiente para exigir tal servicio la presentación al médico o matrona titulares de la libreta de asegurada, acreditándose estar al corriente en el pago de las cuotas.

3. Facilitar a las aseguradas la utilización de sus Clínicas, Hospitales, Salas para partos, Maternidades y demás Obras de Protección a la maternidad y a la infancia. 
(Artículos: 10 del Real Decreto de 22 de marzo de 1929, y 18, 36, 55, 57 y 58 del Reglamento.)

B) Diputaciones. Su colaboración se contrae a facilitar las Clínicaś y demás obras y servicios que señalábamos en el número 3 . $^{\circ}$ para los Ayuntamientos. (Artículo citado del Real Decreto de 1925, y arts. 18, 36, 55 y 59 del Reglamento.)

Todas las aseguradas tienen derecho a estos beneficios, con independencia de que estén o no incluídas en la Beneficencia pública.

3. Subsidio Familiar.-Actuaron las Alcaldías como uno de los centros receptores de las declaraciones que sirvieron para la formación del censo inicial $\left(2 .^{a}\right.$ y $3 .^{\circ}$ disposiciones transitorias del Reglamento y Orden de 7 de febrero de 1939). Por el contrario, al rectificarse éste con referencia a diciembre de 1940, la relación se estableció directamente entre las entidades patronales y la Caja Nacional de Subsidios Familiares (Orden de 28 de octubre de 1940, artículo 1.०).

Corresponde a las Alcaldías el visado de las Declaraciones de familia, extendidas por triplicado, que vinieron a suplir transitoriamente el "Libro de la Familia", y cuya eficacia ha sido prorrogada posteriormente (Art. 47 del Reglamento y Orden del Ministerio del Trabajo de 11 de noviembre de 1939.)

Este visado se extiende también a las Declaraciones de familia que deben suscribir las viudas de trabajadores que hubiesen estado asegurados, cuando, conforme a la Orden de 7 de diciembre de 1939, tengan derecho a ser declaradas subsidiadas; y así mismo a las suscritas por las personas que tengan a su cargo los huérfanos de padre y madre, menores de catorce años, cuando aquél o ésta hayan estado inscritos en el Régimen de Subsidio Familiar. (Arts. $4 .^{\circ}$ y 13 de dicha Orden).

Esta misma Orden preceptúa en su art. 27 que todos los subsidiados a que la misma se refiere, han de presentar anualmente una certificación del Secretaric del Ayuntamiento de su residencia, visada por la Alcaldía, acreditativa de que subsisten las condiciones que determinaron su derecho al percibo del Subsidio.

Los Secretarios de los Ayuntamientos, con dos vocales designadns por las Delegaciones del Instituto Nacional de Previsión, integran las Juntas municipales o vecinales encargadas de formar los censos de trabajadores agrícolas y pecuarios. (Art. $4 .^{\circ}$ de la Ley de $10^{\circ}$ de septiembre de 1939).

4. Seguro de Accidentes del Trabajo.-Corresponde a los Ayunta72 mientos de localidades que no sean capitales de provincia, el reci- 
bir y tramitar a las Inspecciones del Trabajo los partes de accidentes librados por el patrono o entidad que le sustituya en la responsabilidad. (Arts. 183, 184, 191, 192 y 193 del Reglamento de Accidentes del Trabajo en la Industria). Misión receptora les corresponde también respecto a ciertos documentos o declaraciones, como son: el nombramliento por los interesados de facultativos (art. 54), certificaciones médicas (arts. 67 y 71), y declaraciones de hacer efectiva la obligación por responsabilidad del accidente (art. 186).

Ante las Autoridades municipales pueden reclamar los interesados cuando el patrón omita dar conocimiento en forma del accidente o no cumpla las obligaciones legales en caso de éste; debiendo dicha Autoridad proceder inmediatamente a reclamar de la entidad patronal el cumplimiento de la obligación infringida (arts. 210 y siguientes).

Señalemos también el derecho de los patronos y obreros a reclamar la asistencia de los Médicos de la Beneficencia municipal (artículo 57). Terminando esta rápida visión indicando el deber de los Ayuntamientos de abrir un Registro para la inscripción de las farmacias que se comprometan a suministrar los medicamentos necesarios en caso de accidente con arreglo a las tarifas de la Beneficencia municipal de la localidad, o de la vigente en Madrid si en aquella no la hubiere (arts. 75 y 76).

Estas disposiciones son, en general, aplicables también a los accidentes del trabajo en la Agricultura. Pueden verse los arts. 16, 19, 20, 46, 75 y, especiamente, el art. 140, del correspondiente Reglamento; la referencia que hace al Código del Trabajo debe entenderse realizada a la legislación de Accidentes del Trabajo en la Industria vigente hoy.

Angel Olavarria Tellez 